\title{
BMJ Open Retrospective cohort analysis of Spanish national trends of coronary artery bypass grafting and percutaneous coronary intervention from 1998 to 2017
}

\author{
Manuel Carnero Alcazar (D) , ${ }^{1}$ Daniel Hernandez-Vaquero (D) ,2 \\ Hector Cubero-Gallego, ${ }^{3}$ Jose Lopez Menendez, ${ }^{4}$ Miguel Piñon, ${ }^{5}$ \\ Jose Albors Martin, ${ }^{6}$ Gregorio Cuerpo Caballero, ${ }^{7}$ Javier Cobiella Carnicer, ${ }^{1}$ \\ Cristina Villamor, ${ }^{8}$ Alberto Forteza, ${ }^{9}$ Isaac Pascual, ${ }^{10}$ \\ Luis Carlos Maroto Castellanos ${ }^{1}$
}

To cite: Carnero Alcazar M, Hernandez-Vaquero D, Cubero-Gallego $\mathrm{H}$, et al. Retrospective cohort analysis of Spanish national trends of coronary artery bypass grafting and percutaneous coronary intervention from 1998 to 2017. BMJ Open 2021;11:e046141. doi:10.1136/ bmjopen-2020-046141

- Prepublication history and additional materials for this paper is available online. To view these files, please visit the journal online (http://dx.doi. org/10.1136/bmjopen-2020046141).

Received 21 0ctober 2020 Revised 18 February 2021 Accepted 08 March 2021

Check for updates

(C) Author(s) (or their employer(s)) 2021. Re-use permitted under CC BY-NC. No commercial re-use. See rights and permissions. Published by BMJ.

For numbered affiliations see end of article.

Correspondence to Dr Manuel Carnero Alcazar; mcarneroalcazar@gmail.com

\section{ABSTRACT}

Introduction Spain is one of the countries with the lowest rates of revascularisation and highest ratio of percutaneous coronary intervention $(\mathrm{PCl})$ to coronary artery bypass grafting (CABG).

Objectives To investigate the changes and trends in the two revascularisation procedures between 1998 and 2017 in Spain.

Design Retrospective cohort study. Analysis of in-hospital outcomes.

Setting Minimum basic data set from the Spanish National Department of Health: mandatory database collecting information of patients who are attended in the Spanish public National Health System.

Participants 603976 patients who underwent isolated CABG or PCl in the Spanish National Health System. The study period was divided in four 5 -year intervals. Patients with acute myocardial infarction on admission were excluded.

Primary and secondary outcomes We investigated the volume of procedures nationwide, the changes of the risk profile of patients and in-hospital mortality of both techniques.

Results We observed a 2.2-fold increase in the rate of any type of myocardial revascularisation per million inhabitants-year: 357 (1998) to 776 (2017). 93682 (15.5\%) had a coronary surgery. $\mathrm{PCI}$ to $\mathrm{CABG}$ ratio rose from 2.2 (1998-2002) to 8.1 (2013-2017). Charlson's index increased by 0.8 for CABG and 1 for PCl. The median annual volume of $\mathrm{PCl} /$ hospital augmented from 136 to 232, while the volume of CABG was reduced from 137 to 74 . In the two decades, we detected a significant reduction of CABG in-hospital mortality ( $6.5 \%$ vs $2.6 \%$, $p<0.001)$ and a small increase in $\mathrm{PCl}(1.2 \%$ vs $1.5 \%$, $p<0.001)$. Risk adjusted mortality rate was reduced for both CABG (1.51 vs $0.48, p<0.001)$, and $\mathrm{PCl}$ ( 1.42 vs $1.05, p<0.001)$.

Conclusion We detected a significant increase in the volume of revascularisations (particularly PCI) in Spain. Risk-adjusted in-hospital mortality was significantly reduced.
Strengths and limitations of this study

- This is the first study to investigate the nationwide changes and trends in coronary revascularisation in Spain during the past two decades.

- It was based on a very large and detailed administrative database which included most of the episodes of patients who have been admitted to any public National Health Service hospital between 1998 and 2017.

- Follow-up information is not available.

- The analysis might be biased by administrative information coding errors and missings.

- However, no other source of information allows to perform a long-term nationwide investigation like this.

\section{INTRODUCTION}

Surgical and percutaneous myocardial revascularisation have demonstrated to improve symptoms and life expectancy in patients with advanced coronary artery disease. In the vast majority of patients with ST-elevation acute coronary syndrome, percutaneous coronary intervention (PCI) is the preferred strategy. ${ }^{1}$ However, in chronic stable angina or non-ST elevation acute coronary syndromes, the choice between PCI and coronary artery bypass grafting (CABG) depends on multiple factors. In this scenario, the best therapeutic option for each patient must be decided ${ }^{12}$ by a multidisciplinary 'Heart Team'.

Many authors have investigated large national registries and analysed the changes of both techniques over time and the distribution of CABG and PCI across different regions and countries. ${ }^{3-6}$ Spain is, according to the Organisation for Economic Co-operation and Development (OECD) ${ }^{6}$ one of 
the European countries with the lowest rates of revascularisation and the one with the highest ratio of PCI to CABG. The causes of the magnitude of this disbalance have never been studied in depth. Moreover, there is no robust evidence on the evolution of the two techniques in terms of their results and variability, nor the risk profile of patients with CABG and PCI in the Spanish National Health System (NHS).

In Spain, there are no patient-level clinical registries specifically dedicated to patients with coronary artery disease undergoing myocardial revascularisation. The Spanish Society of Thoracic and Cardiovascular Surgery and the Spanish Society of Cardiology annually report the national volumes and outcomes of CABG and PCI. ${ }^{78}$ However, these reports are based on voluntary, aggregated and unaudited information submitted by hospitals. On the other hand, the healthcare centres of the Spanish NHS have to report the administrative information of all admitted patients to a mandatory nationwide registry: The minimum basic data set (MBDS) from the Department of Health. The MBDS is a public open access database which stores individual and anonymised data from all discharge reports from all the NHS episodes, coded according to the International Classification of Diseases (ICD). Despite the fact that the use of non-specific administrative sources, such as this one, for the analysis of clinical indicators in the field of cardiology is controversial, ${ }^{9}$ different studies based on the MBDS have validated its usefulness to analyse the results of clinical processes in Spain. ${ }^{10-14}$

We set out to study the evolution of CABG and PCI in Spain between 1998 and 2017 with the information obtained from the MBDS from the Department of Health of Spain. Specifically, we analysed the volume of CABG and PCI, the changes in the risk profile of patients and hospital mortality in the two revascularisation strategies. It was not the objective of this study to compare the results of both techniques, taking into account that they have different indications and that follow-up information is not available.

\section{MATERIALS AND METHODS}

\section{Sources of information and patient selection}

Data were obtained from the MBDS from the Department of Health of Spain. This research was carried out according to the STROBE (Strengthening the Reporting of OBservational studies in Epidemiology) recommendations.

The patient selection algorithm can be seen in figure 1 . We investigated all the outpatient or hospitalisation episodes of the Spanish NHS from 1998 to 2017 in which a CABG or PCI procedure had been carried out. Those episodes during which patients underwent concomitant procedures were excluded (see online supplemental table 1 ICD-9 and ICD-10 codes).

Likewise, all episodes with an acute myocardial infarction/acute coronary syndrome with ST-segment elevation as the primary diagnosis on admission (see online

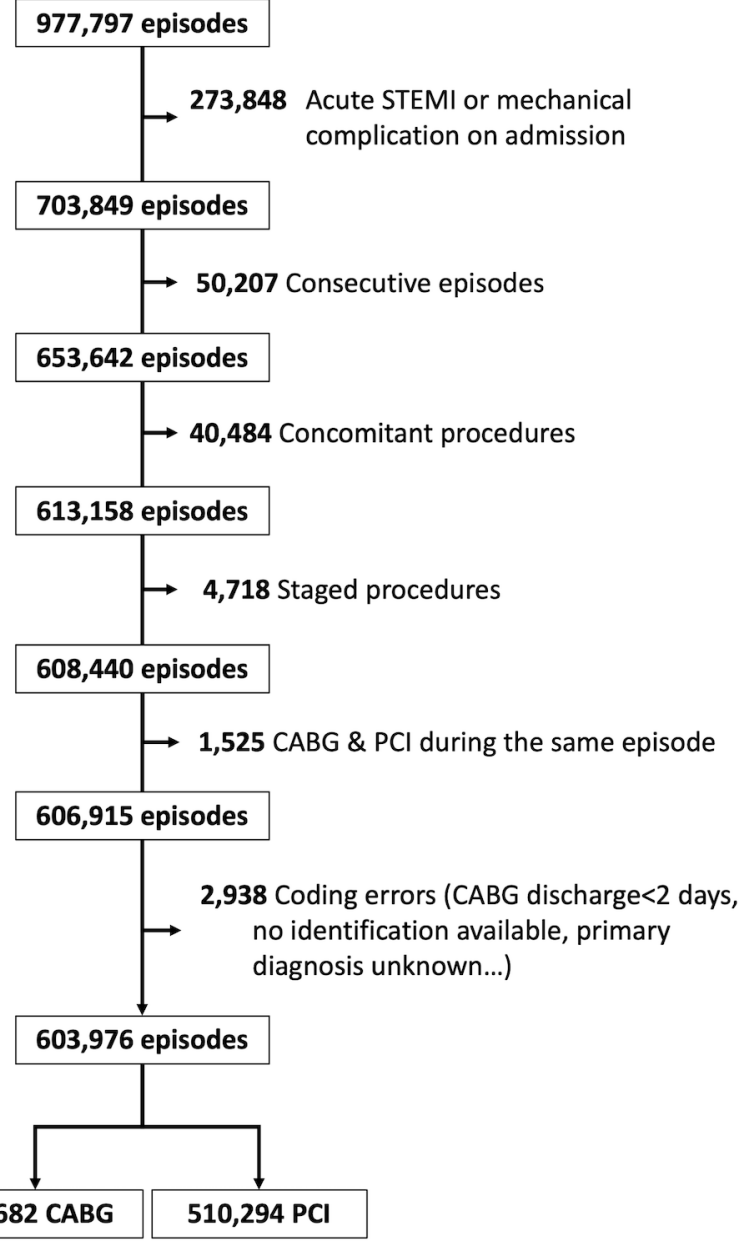

Figure 1 Flow diagram. Selection of episodes. CABG, coronary artery bypass grafting; $\mathrm{PCl}$, percutaneous coronary intervention.

supplemental table 1) were excluded, as those with both types of revascularisation. In addition, to avoid possible coding errors, patients younger than 18 years of age or older than 100 years of age, patients operated on CABG in centres without CABG or who underwent PCI in centres without PCI were also discarded. Patients discharged alive earlier than 2 days after CABG were also considered as coding errors. The episodes corresponding to patients who were transferred to another centre and consecutive planned revascularisations episodes were consolidated into a single episode. ${ }^{14}$ Each episode corresponds to a single patient, but a patient might have more than one episode. Given that we analysed in-hospital outcomes, different consolidated episodes will be considered as different patients for the purpose of this study.

The full period of time (1998-2017) was divided in four 5-year intervals (1998-2002, 2003-2007, 2008-2012 and 2013-2017).

\section{Patient and public involvement}

No patient was actively involved in the study. Information regarding the delivered healthcare to the patients included in this investigation was obtained de-identified from the Spanish Department of Health 
National volume of revascularisation procedures and risk profile of the patients

We investigated the absolute number of CABG and PCI per year, the number of procedures per million of inhabitants and the changes in the PCI/CABG ratio. Further analyses to investigate the trends in the indexed volume of each type of procedure were also performed according to sex and age. To estimate the nationwide population, data were extracted from the National Institute of Statistics. ${ }^{15}$

Healthcare centres were classified according to the volume of procedures per year. Thus, for both CABG and PCI, hospitals were divided into four groups according to the quartile of the volume of PCI or CABG interventions that they performed in each year: low volume (quartile 1 ), low-intermediate volume (quartile 2), high-intermediate volume (quartile 3 ) and high volume (quartile 4).

Patients were classified into four groups according to their age ( $\leq 60,>60$ and $\leq 70,>70$ and $\leq 80$ and $>80$-year-old). We analysed the evolution of the prevalence of various comorbidities age-modified Charlson's index was calculated. ${ }^{1617}$ In addition, the individual components of this score (previous history of myocardial infarction, kidney disease, diabetes and so on) and other procedural variables were analysed throughout the study period (see table 1).

\section{Mortality}

We analysed in-hospital non-adjusted and adjusted mortality for PCI and CABG and its changes over the study period.

\section{Statistical analysis}

Categorical variables were represented with absolute and relative frequencies (\%) and were compared with the $\chi^{2}$ test. The normality of the quantitative variables was analysed with P-P plots, and they were expressed with mean and SD or median and IQR. Imputation was not made for missing values. Statistics were estimated using available data. Quantitative variables were compared among the periods of the study with an analysis of variance or non-parametric comparison of medians. Contrasts were performed to investigate the presence of a linear trends (LT). The relative risk reduction (RRR) and OR were used to represent the strength of association between different variables and mortality.

We investigated factors associated to mortality for each type of revascularisation. For this purpose, we created multivariable models including variables with theoretical value and variables related to mortality (statistical significance $\mathrm{p}<0.1$ ) in an univariable analysis. The best models were selected based on the value of the Akaike information criterion, adjusted $\mathrm{R}^{2}$ and their area under the curve.

Subsequently, we estimated two new models to predict mortality after PCI and CABG, respectively, excluding the time period. We divided the observed mortality in each year for PCI and CABG by that expected according to the corresponding model. In this way, we analysed the evolution of risk-adjusted mortality rate (RAMR) over time. ${ }^{14}$
Statistical analysis was performed with Stata V.15.0 (StataCorp, College Station, Texas, USA).

\section{RESULTS}

\section{Study population}

Almost one million (977 797) episodes of CABG or PCI were included in the study. Thirty-eight per cent (373 831) were excluded, and 603967 were considered for the purpose of this study (see figure 1 and online supplemental figure 1 and table 2). Of these, 93682 $(15.5 \%)$ had CABG and $510294(84.5 \%)$ had PCI. There was a linear increase $\left(\mathrm{p}_{\mathrm{LT}}<0.001\right)$ in the PCI/ CABG ratio: 1998-2002: 2.2 (69\% PCI vs 31\% CABG), 2003-2007: 5 (83.3\% PCI vs 16.7\% CABG), 2008-2012: 7.6 (88.3\% PCI vs 11.7\% CABG) and 2013-2017: 8.1 (89\% PCI vs $11 \%$ CABG) (table 1). In the general sample, an increase in the number of revascularisations was observed, mainly due to a higher number of PCI and a drop in CABG (figure 2A). We observe relevant differences in the volume of procedures by sex. Overall, more PCI and CABG were performed in men than in women, but the difference increased more markedly in PCI (figure 2B). Regarding the type of procedure by age range, PCI increased in all age ranges, although the increase was more pronounced in those over 60 years of age. On the contrary, CABG significantly decreased among those between 60 and 80 years of age and experienced a slight decrease in the the youngest population group (figure 3). Absolute number of procedures and according to type of coronary syndrome is shown in online supplemental figures 2 and 3.

The risk profile of patients worsened throughout the study period (table 1). In PCI and CABG groups, we observed a higher mean age and a greater prevalence of risk factors such as previous myocardial infarction, heart failure, peripheral vascular disease, diabetes or chronic obstructive pulmonary disease (COPD). Consequently, Charlson's index rose up from 2.7 to $3.5\left(\mathrm{p}_{\mathrm{LT}}<0.001\right)$ in CABG and from 2.6 to $3.6\left(\mathrm{p}_{\mathrm{LT}}<0.001\right)$ in PCI (table 1 and online supplemental figure 4$)$.

We detected a significant growth of PCI in centres without CABG: 1998-2002 (17.4\%) and 2013-2017 $(41.1 \%)\left(\mathrm{p}_{\mathrm{LT}}<0.001\right)$. The proportion of patients who had three or more coronary arteries revascularised was higher in the CABG group $(40.5 \%$ vs $7.1 \%$, p<0.001). We observed a linear increase in the use of bilateral internal thoracic arteries (8\% vs $\left.23.6 \%, \mathrm{p}_{\mathrm{LT}}<0.001\right)$, and off-pump CABG (31.3\% vs $\left.34.2 \%, \mathrm{p}_{\mathrm{LT}}<0.001\right)$ from the first to the last period. Similarly, an increase in drug eluting stents and a decrease of bare metal stents was observed among patients with PCI $\left(\mathrm{p}_{\mathrm{LT}}<0.001\right)$. The number of outpatient percutaneous procedures was small but increased in the last two periods (see table 1). The proportion of patients with previous 


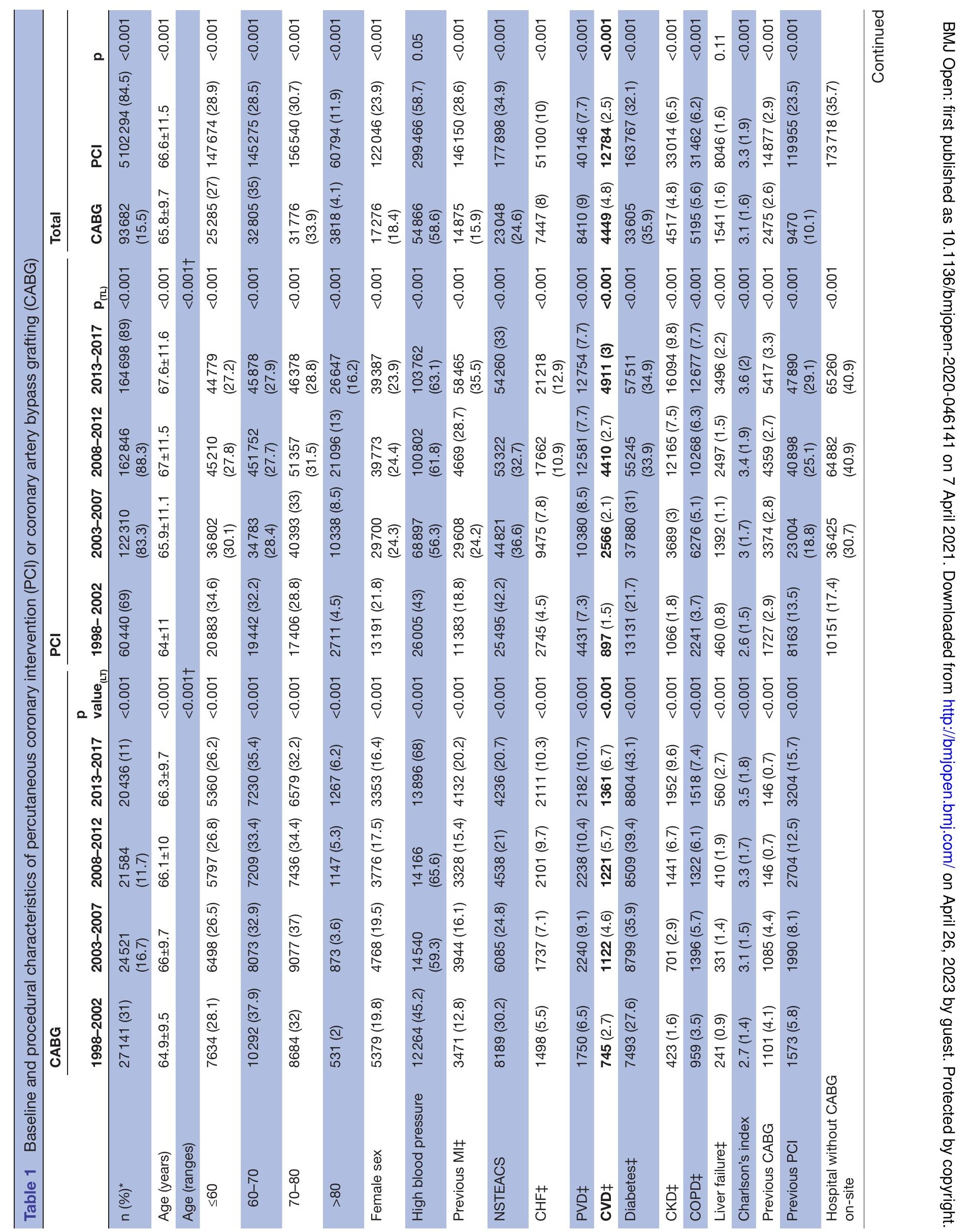




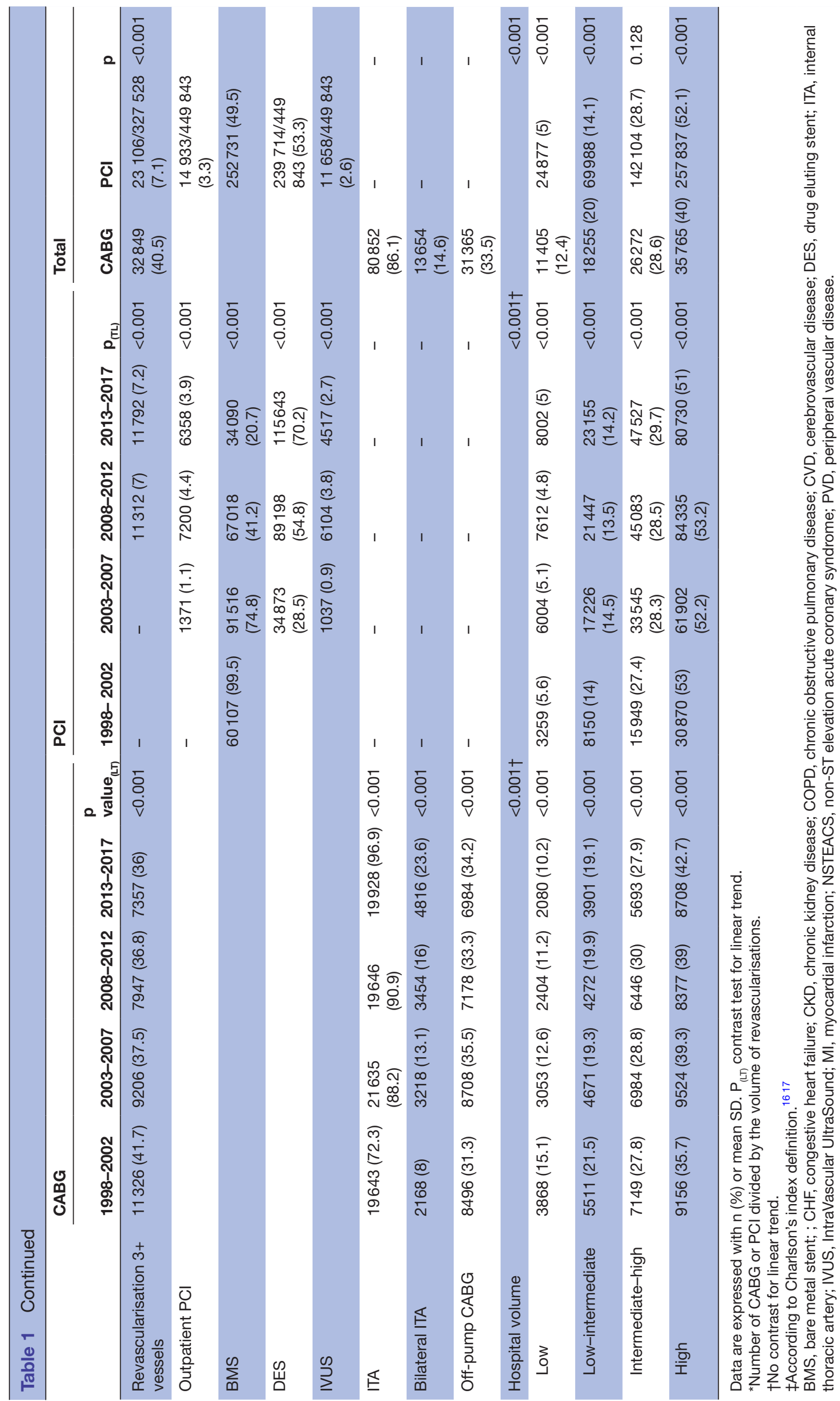



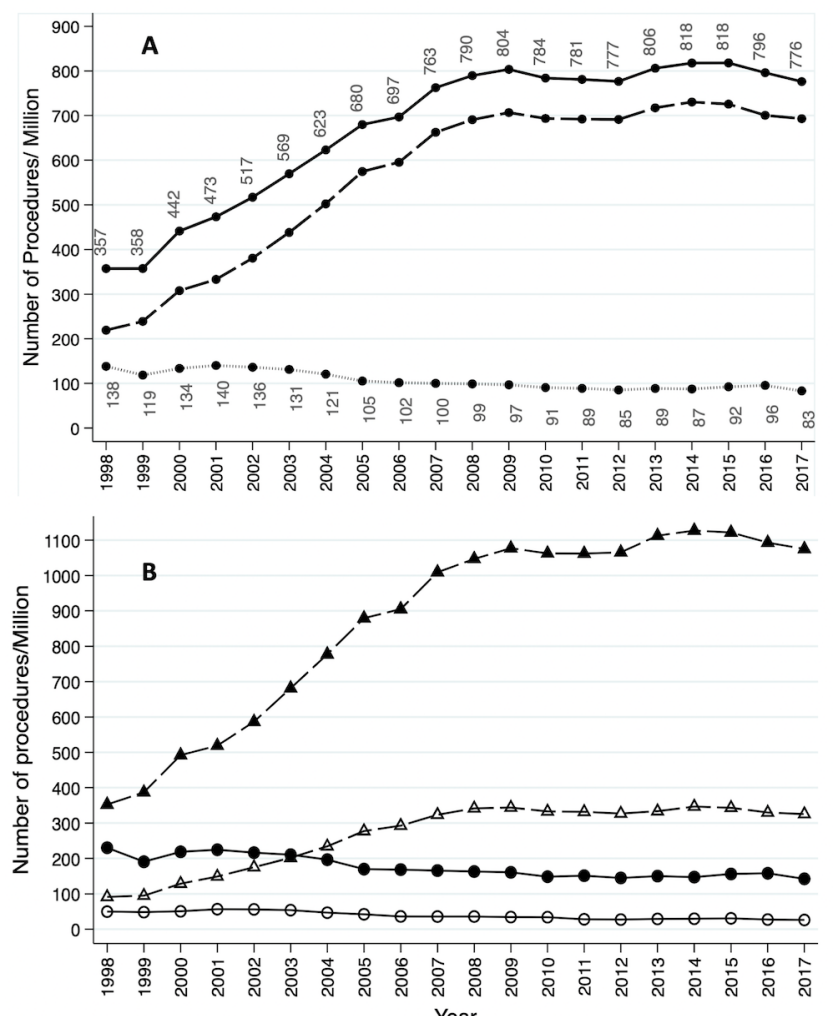

Year

\begin{tabular}{|c|c|}
\hline$\bullet$ & $-C A$ \\
\hline
\end{tabular}

Figure 2 Number of procedures per million inhabitants and year. (A) Volume of procedures per year. Number of total revascularisations and CABG are shown. (B) Number of procedures by sex and per million inhabitants. The number of procedures of each type is represented by sex and per million inhabitants of each sex throughout the study period. CABG, coronary artery bypass grafting; $\mathrm{PCl}$, percutaneous coronary intervention.

revascularisation increased linearly throughout the study: (1998-2002: 13.9\%; 2003-2007: 19.4\%; $2008-$ 2012: 25.3\%; 2013-2017: 29.4\%; $\left.\mathrm{p}_{\mathrm{LT}}<0.001\right)$. Most of this increase was due to a growth of revascularised patients with previous PCI, while the number of patients undergoing CABG or PCI with a history of previous surgery decreased or increased minimally, respectively (table 1 and online supplemental figure $5)$.

We observed a growth of episodes of patients with diabetes and an increase of percutaneous procedures in this subset. Specific information on patients with diabetes can be found in online supplemental table 3 .

\section{Mortality}

Among patients undergoing CABG, a reduction in nonadjusted in-hospital mortality was observed between 1998 and 2017: $6.5 \%$ vs $2.6 \%\left(\mathrm{p}_{\mathrm{LT}}<0.001\right.$; RRR $-60 \%, 95 \%$ CI $-64.8 \%$ to $-55.2 \%)$. Mortality among patients undergoing PCI raised slightly from $1.2 \%$ to $1.5 \%\left(\mathrm{p}_{\mathrm{LT}}<0.001\right.$; $\mathrm{RRR}+25 \%, 95 \%$ CI $22.3 \%$ to $27.6 \%$ ) (figure $4 \mathrm{~A}$ ).
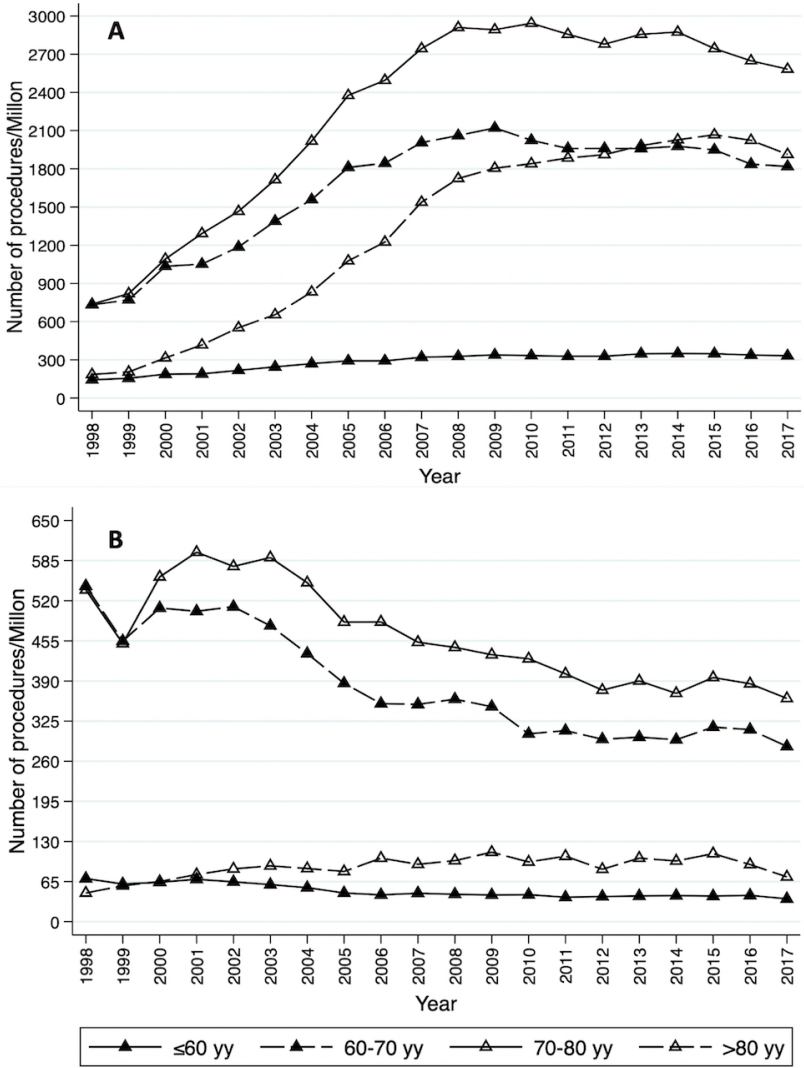

Figure 3 Number of procedures per million inhabitants and year in age ranges. (A) Percutaneous coronary intervention.

(B) Coronary artery bypass grafting.

Table 2 shows factors independently associated to in-hospital mortality after CABG or PCI. Most of the factors increased mortality regardless of the type of revascularisation (COPD, age, previous infarction, heart failure and so on). The effect of some variables changed depending on the type of revascularisation such as the hospital volume of procedures and period of study. PCI mortality in centres without CABG was lower than in centres with CABG on-site (OR $0.86,95 \%$ CI 0.8 to 0.92 , $\mathrm{p}<0.001$ ) (more information can be found in online supplemental material).

Information regarding the estimation of RAMR is shown in online supplemental tables 4 and 5 . A decrease in RAMR was detected in patients with both CABG and PCI. In the case of coronary surgery, the RAMR decreased from 1.51 to $0.48\left(\mathrm{p}_{\mathrm{LT}}<0.001\right)$, and in the case of PCI from 1.42 to $1.05\left(\mathrm{p}_{\mathrm{LT}}<0.001\right)$ between 1998 and 2017, respectively (see figure $4 \mathrm{~B}$ ).

\section{Volume of activity and mortality by centre}

The number of centres with CABG and PCI on-site grew from $37(1998-2002)$ to $48 \quad(2013-2017)\left(\mathrm{p}_{\mathrm{LT}}<0.001\right)$ (online supplemental table 6 and figure 6 ). The number of centres with PCI but without CABG on-site increased from 25 (1998) to 96 (2017). We observed a higher median volume of PCI per centre from 136 to $232\left(\mathrm{p}_{\mathrm{LT}}<0.001\right)$ and a decrease in CABG from 137 to $74\left(\mathrm{p}_{\mathrm{TT}}<0.001\right)$ between 1998 and 2017 (online supplemental material). The 

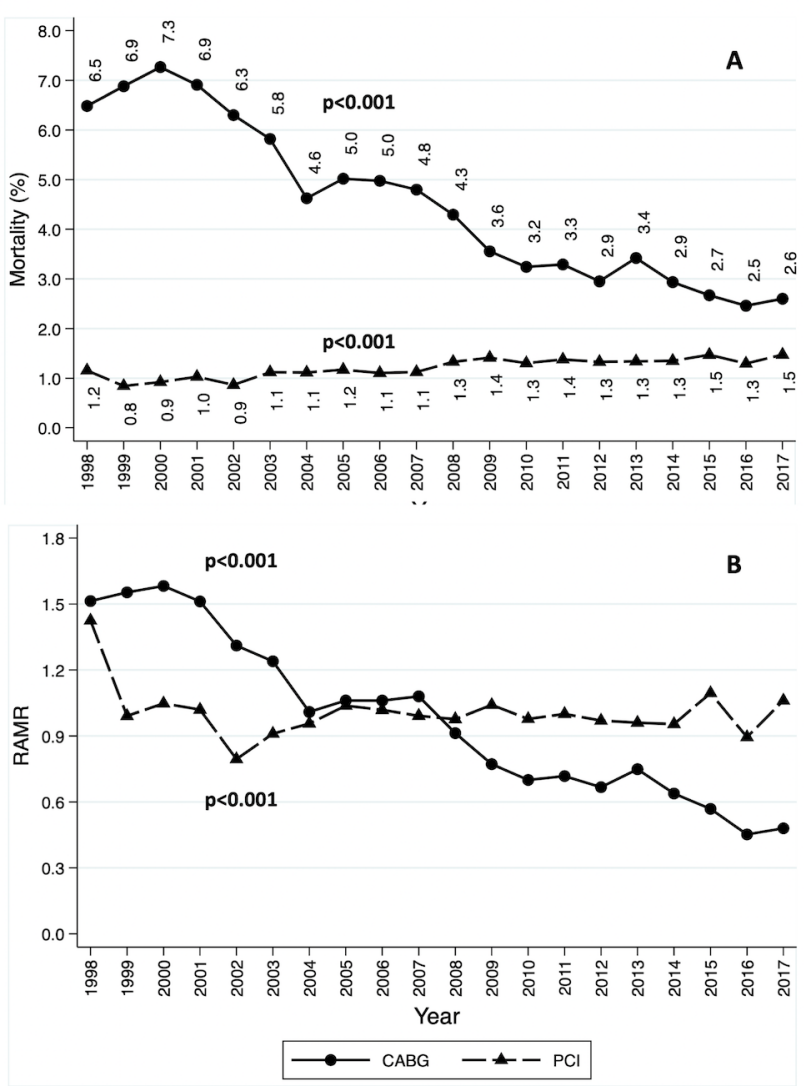

Figure 4 Non-adjusted and adjusted in-hospital mortality. CABG, coronary artery bypass grafting; $\mathrm{PCl}$, percutaneous coronary intervention; RAMR, risk-adjusted mortality rate.

volume of interventions was independently associated to a lower in-hospital mortality for CABG and a higher mortality after PCI (see table 2 ).

\section{DISCUSSION}

Between 1998 and 2017, in Spain, the volume of revascularisations in patients without ST-elevation myocardial infarction increased to 776 per million inhabitants (see figure 2). However, these rates are very low as compared with other countries. For example, in the USA, the number of CABG per million inhabitants in 2007-2008 was 1081 per year, while that of PCI was 3667 per year. ${ }^{18}$ In Germany, in 2013, the proportion of revascularisations per 100000 inhabitants was three times higher than in Spain. ${ }^{6}$ Although the differences can be explained by the lower prevalence of coronary heart disease in Spain, there are other factors that may influence such as a greater difficulty in accessing the healthcare system for patients or a less frequent indication for revascularisation.

In addition, there was, over the past 20 years, a $27.7 \%$ reduction in the volume of CABG (5506 in 1998 vs 3872 in 2017) and a 3.7-fold increase of PCI volume (8735 in 1998 vs 32272 in 2017). During such a long period of time, the indications for CABG and PCI have varied, mainly in patients with stable one-vessel or two-vessel coronary artery disease, with percutaneous revascularisation being the most frequently indicated nowadays. In patients with left main or three-vessel disease, the indication for PCI has also gained strength, although with less intensity. These changes have been mainly due to the development of new percutaneous devices and the optimisation of medical treatment. ${ }^{119}$ Even so, different studies have consistently continued to detect the benefit of CABG in patients with more complex coronary disease. ${ }^{20}$

The PCI/CABG ratio in the last period of the study was 8.1. In the 2016 'Health at a Glance' report, the PCI/ CABG ratio was 7.3 in Spain, close to that observed in this study and more than double the average of the countries included in that report: $3.55 .{ }^{6}$ Similar changes have happened in other countries. For example, the analysis of the US National Inpatient Sample registry found a decline in the volume of CABG of $116 \%$ between 1998 and $2015^{21}$ and $14 \%$ between 2001 and 2007 with a stabilisation of the volume of PCI. ${ }^{18}$ The New York State registry detected an increase in the PCI/CABG ratio between 1994 and 2008 from 1.12 to $5.14 .^{5}$ The ratio observed in the present study, however, is difficult to compare since we have excluded revascularisations among patients with acute myocardial infarction which were considered in other reports. ${ }^{6}$ Therefore, the PCI to CABG ratio in Spain might be even higher. This large difference in Spain may be due to several factors such as difficulties in accessing one of the therapies, poor adherence to therapeutic recommendations, underindication of revascularisation or the characteristics of coronary heart disease in the Spanish population being different from those in other developed countries. Furthermore, we detected large and increasing differences between men and women depending on the type of revascularisation (see figure 2), which probably denotes a limited access of women to the healthcare system.

A significant worsening of the risk profile has been observed for patients with both PCI and CABG: $14 \%$ raise in the prevalence of diabetes, sixfold increase of patients with severe chronic kidney disease or COPD by 2 (see table 1). In general, the poorer risk profile of patients is consistent with a progressive ageing and a higher prevalence and severity of cardiovascular risk factors observed in Spain and other countries. ${ }^{22-24}$ Despite the conflicting evidence on the benefit of off-pump CABG or multiple arterial grafts revascularisation, in Spain there has been an increase in the number of patients operated on with two or more internal thoracic arterial grafts $(8 \%$ in the first period vs 23.6\% between 2013 and $\left.2017\left(\mathrm{p}_{\mathrm{LT}}<0.001\right)\right)$ or off pump (31.3\% vs $34.2 \%$ in the first and last period, respectively, $\left.\mathrm{p}_{\mathrm{LT}}<0.001\right) .{ }^{25}{ }^{26}$ Regarding PCI, revascularisations with drug eluting stents grew as bare metal stents became less frequently used.

The increase in the proportion of patients requiring a new revascularisation increased throughout the study (see table 1 and online supplemental material). This increase was more notable in PCI and, above all, at the expense of a previous percutaneous revascularisation. This finding is consistent with the sustained increase in revascularisations over time, the lower need for re-intervention after 


\begin{tabular}{|c|c|c|c|c|c|}
\hline \multicolumn{3}{|l|}{ CABG } & \multicolumn{3}{|l|}{$\mathrm{PCl}$} \\
\hline Variable & OR $(95 \% \mathrm{Cl})$ & $P$ value & Variable & OR $(95 \% \mathrm{Cl})$ & $P$ value \\
\hline \multicolumn{3}{|c|}{ Hospital volume of CABG (as compared with low volume centres) } & \multicolumn{3}{|c|}{ Hospital volume of $\mathrm{PCI}$ (as compared with low volume centres) } \\
\hline Low-intermediate & $0.86(0.77$ to 0.95$)$ & 0.004 & Low-intermediate & 1.4 (1.18 to 1.68$)$ & $<0.001$ \\
\hline COPD & 1.35 (1.2 to 1.53$)$ & $<0.001$ & COPD & 1.25 (1.15 to 1.35$)$ & $<0.001$ \\
\hline \multicolumn{3}{|c|}{ Age (as compared with <60) } & \multicolumn{3}{|l|}{ Age (as compared with $<60$ ) } \\
\hline $60-70$ & $1.72(1.55$ to 1.91$)$ & $<0.001$ & $60-70$ & 1.69 (1.54 to 1.85$)$ & $<0.001$ \\
\hline $70-80$ & $3.02(2.73$ to 3.33$)$ & $<0.001$ & $70-80$ & 2.6 (3.38 to 2.84$)$ & $<0.001$ \\
\hline $\begin{array}{l}\text { NSTEACS as primary } \\
\text { diagnosis }\end{array}$ & $1.2(1.12$ to 1.28$)$ & $<0.001$ & & & \\
\hline $\mathrm{CHF}$ & 3.21 (2.96 to 3.49$)$ & $<0.001$ & $\mathrm{CHF}$ & 4.63 (4.39 to 4.9$)$ & $<0.001$ \\
\hline PVD & $1.43(1.29$ to 1.57$)$ & $<0.001$ & PVD & 1.24 (1.15 to 1.34$)$ & $<0.001$ \\
\hline CVD & $1.72(1.52$ to 1.94$)$ & $<0.001$ & CVD & 2.29 (2.08 to 2.52$)$ & $<0.001$ \\
\hline CKD & 1.75 (1.55 to 1.99$)$ & $<0.001$ & CKD & $1.56(1.45$ to 1.67$)$ & $<0.001$ \\
\hline On-pump CABG & 1.09 (1.02 to 1.17$)$ & 0.017 & & & \\
\hline Bilateral ITA & 0.8 (0.71 to 0.89$)$ & 0.042 & & & \\
\hline \multicolumn{3}{|c|}{ Period of study (as compared with 1997-2002) } & \multicolumn{3}{|c|}{ Period of study (as compared with 1997-2002) } \\
\hline 2013-2017 & & & DES & 0.41 (0.38 to 0.45$)$ & 0.001 \\
\hline
\end{tabular}

BMS, bare metal stent; CABG, coronary artery bypass grafting; CHF, congestive heart failure; CKD, chronic kidney disease; COPD, chronic obstructive pulmonary disease; CVD, cerebrovascular disease; DES, drug eluting stent; ; ITA, internal thoracic artery; MI, myocardial infarction; NSTEACS, non-ST elevation acute coronary syndrome; PCI, percutaneous coronary intervention; PVD, peripheral vascular disease.

CABG and the preference for percutaneous approaches in the global series ${ }^{12681920}$ (table 1 and online supplemental figure 5).

Mortality after CABG in Spain has decreased from $6.5 \%$ in 1998 to $2.6 \%$ in 2017 and is now similar to that of other countries. ${ }^{22}$ The strong reduction of mortality is a common finding too: for example, the registry for New South Wales detected a reduction of in-hospital mortality after CABG of $30 \%$ between 2000 and $2013 .{ }^{27}$ A significant fourfold reduction in risk-adjusted mortality was observed too between 1998 and 2017 (0.44) (1.55 to 0.44 $\left.\left(\mathrm{p}_{\mathrm{LT}}<0.001\right)\right)$.

Hospital mortality after PCI in Spain was similar to that of other developed countries, ${ }^{28}{ }^{29}$ and slightly grew throughout the series. When adjusting for patient comorbidities and other confounding factors, the RAMR was reduced by almost $40 \%$ (1.42 to $\left.1.05\left(\mathrm{p}_{\mathrm{LT}}<0.001\right)\right)$.
We have detected a fourfold growth of the number of centres that perform PCI without CABG on site (see online supplemental table 6). Between 2013 and 2017, $41.1 \%$ of the patients treated with PCI were revascularised in a centre without coronary surgery. In addition, there has been a very significant reduction in the median number of $\mathrm{CABG}$ procedures per centre between the first and last period of the study (130.5 vs $\left.75.5, \mathrm{p}_{\mathrm{LT}}<0.001\right)$. This volume of interventions per centre is different from that reported by Goicolea et $a l^{14}$ who detected a mean number of CABG procedures of 95 per year between 2013 and 2015. Goicolea et al misclassified procedures such as combined surgery of the aorta, pericardium, ventricular remodelling or cardiac arrhythmias as isolated coronary surgery interventions, which can explain the differences. In any case, the volume of CABG or PCI per centre in Spain is very low. For example, in Europe, hospitals with 
an intermediate volume of CABG perform between 125 and 450 procedures per year ${ }^{30}$ and the EACTS/ESC Myocardial Revascularisation Guidelines recommend a minimum of 200 isolated CABG interventions to maintain viable coronary surgery programmes. ${ }^{1}$

There is an important relationship between the volume of CABG per centre and in-hospital mortality, such that as the volume of the centres increases, mortality decreases. On the contrary, mortality after PCI increases as the volume of interventions increases (table 2 and online supplemental material). The latter can be explained by the fact that patients referred to centres with greater activity may have anatomical characteristics or comorbidities that confer a greater risk, and which have not been adequately contemplated in this study (ie, left main disease, severely calcified coronary arteries, poor left ventricular function and so on).

\section{Conclusions}

From 1998 to 2017 there has been a significant increase in the volume of revascularisations in Spain. This growth has been uneven, with more PCI and a gradual reduction in CABG. Risk-adjusted mortality has been significantly reduced in both arms, although the reduction has been particularly pronounced among surgically revascularised patients. Finally, in Spain, there is not an adequate balance between the volume of revascularisations and the number of hospitals, with centres with a low number of CABG procedures and a great proportion of hospitals with PCI programmes but without CABG on-site.

\section{Limitations}

These conclusions have to be taken with caution due to possible coding biases and others inherent to administrative databases analyses. Beyond a real change, the variation in the prevalence of comorbidities can be also partially explained by changes and errors in coding throughout the study period. Surgical turndowns are known to have higher risk despite risk adjustment, but they could not be identified in this data set. We could not estimate operative or cardiovascular risks according to validated clinical scores in cardiac surgery or cardiology (such as EuroSCORE, Framingham Risk Score or NCDR CathPCI Mortality risk) given that the items of these scores are not available in the MBDS. The MBDS does not contain information on private activity in Spain.

\footnotetext{
Author affiliations

${ }^{1}$ Cardiac Surgery, Hospital Clínico Universitario San Carlos Instituto Cardiovascular, Madrid, Comunidad de Madrid, Spain

${ }^{2}$ Cardiac Surgery, Hospital Universitario Central de Asturias, Oviedo, Asturias, Spain

${ }^{3}$ Cardiology, Unit of Interventional Cardiology, Hospital del Mar, Barcelona, Catalunya, Spain

${ }^{4}$ Cardiac Surgery, Hospital Ramon y Cajal, Madrid, Spain

${ }^{5}$ Cardiac Surgery, Alvaro Cunqueiro Hospital, Vigo, Galicia, Spain

${ }^{6}$ Cardiac Surgery, Hospital Universitario del Vinalopó, Elche, Alicante, Spain

${ }^{7}$ Cardiac Surgery, Hospital General Universitario Gregorio Marañón, Madrid, Spain

${ }^{8}$ Internal Medicine, Hospital Clinico Universitario San Carlos, Madrid, Spain

${ }^{9}$ Cadiac Surgery, Puerta del Hierro University Hospital of Majadahonda,

Majadahonda, Madrid, Spain
}

${ }^{10}$ Cardiology, Unit of Interventional Cardiology, Hospital Universitario Central de Asturias, Oviedo, Asturias, Spain

\section{Twitter Manuel Carnero Alcazar @manuel_carnero}

Contributors MCA, DH-V, HC-G, LCMC and JLM contributed to developing the design of the study. MCA and LCMC requested the information from the Spanish Department of Health. MCA, MP, JAM, CV, IP and GCC contributed to interpreting the data. MCA, JCC and DH-V performed the statistical analysis. AF and LCMC contributed to the critical review of the paper. MCA is the guarantor of this work and assumes full responsibility for the conduct of the study.

Funding The authors have not declared a specific grant for this research from any funding agency in the public, commercial or not-for-profit sectors.

Competing interests None declared.

Patient consent for publication Not required.

Ethics approval This study was approved by the Institutional Review Board and Ethics Committee at Hospital Clínico San Carlos (Madrid, Spain).

Provenance and peer review Not commissioned; externally peer reviewed.

Data availability statement Data are available in a public, open access repository. Extra data can be accessed via the Dryad data repository at http://datadryad.org/ with the doi:10.5061/dryad.gqnk98smk.

Supplemental material This content has been supplied by the author(s). It has not been vetted by BMJ Publishing Group Limited (BMJ) and may not have been peer-reviewed. Any opinions or recommendations discussed are solely those of the author(s) and are not endorsed by BMJ. BMJ disclaims all liability and responsibility arising from any reliance placed on the content. Where the content includes any translated material, BMJ does not warrant the accuracy and reliability of the translations (including but not limited to local regulations, clinical guidelines, terminology, drug names and drug dosages), and is not responsible for any error and/or omissions arising from translation and adaptation or otherwise.

Open access This is an open access article distributed in accordance with the Creative Commons Attribution Non Commercial (CC BY-NC 4.0) license, which permits others to distribute, remix, adapt, build upon this work non-commercially, and license their derivative works on different terms, provided the original work is properly cited, appropriate credit is given, any changes made indicated, and the use is non-commercial. See: http://creativecommons.org/licenses/by-nc/4.0/.

ORCID iDs

Manuel Carnero Alcazar http://orcid.org/0000-0001-5045-5765

Daniel Hernandez-Vaquero http://orcid.org/0000-0003-3518-6629

\section{REFERENCES}

1 Neumann FJ, Sousa-Uva M, Ahlsson A, et al. ESC/EACTS guidelines on myocardial revascularization. Eur Heart J 2018;2019:87-165.

2 Mohr FW, Morice M-C, Kappetein AP, et al. Coronary artery bypass graft surgery versus percutaneous coronary intervention in patients with three-vessel disease and left main coronary disease: 5 -year follow-up of the randomised, clinical SYNTAX trial. Lancet 2013;381:629-38.

3 Blumenfeld O, Na'amnih W, Shapira-Daniels A, et al. Trends in coronary revascularization and ischemic heart disease-related mortality in Israel. J Am Heart Assoc 2017;6:e004734.

4 Epstein AJ, Polsky D, Yang F. Coronary revascularization trends in the United States, 2001-2008. JAMA 2011;305:1769-76.

5 Ko W, Tranbaugh R, Marmur JD, et al. Myocardial revascularization in New York state: variations in the PCl-to-CABG ratio and their implications. J Am Heart Assoc 2012;1:e001446.

6 Health at a Glance: Europe 2016. State of health in the EU cycle. Available: https://ec.europa.eu/health/sites/health/files/state/docs/ health_glance_2016_rep_en.pdf [Accessed 28 Apr 2020].

7 Cuerpo G, Carnero M, Hornero Sos F, et al. Cirugía cardiovascular en España en El año 2018. Registro de intervenciones de la Sociedad Española de Cirugía Torácica-Cardiovascular. Cir Cardiov 2019;26:248-64.

8 Cid Álvarez AB, Rodríguez Leor O, Moreno R, et al. Registro Español de Hemodinámica Y Cardiología Intervencionista. XXVII Informe Oficial de la Sección de Hemodinámica Y Cardiología Intervencionista de la Sociedad Española de Cardiología (19902017). Revista Española de Cardiología 2018;71:1036-46. 
9 Mack MJ, Herbert M, Prince S, et al. Does reporting of coronary artery bypass grafting from administrative databases accurately reflect actual clinical outcomes? J Thorac Cardiovasc Surg 2005;129:1309-17.

10 Íñiguez Romo A, Bertomeu Martínez V, Rodríguez Padial L, et al. The recalcar project. healthcare in the cardiology units of the Spanish National health system, 2011 to 2014. Rev Esp Cardiol 2017;70:567-75.

11 Rodríguez-Padial L, Bertomeu V, Elola FJ, et al. Quality improvement strategy of the Spanish Society of cardiology: the RECALCAR registry. J Am Coll Cardiol 2016;68:1140-2.

12 Bertomeu V, Cequier Ángel, Bernal JL, et al. In-hospital mortality due to acute myocardial infarction. relevance of type of hospital and care provided. RECALCAR study. Rev Esp Cardiol 2013;66:935-42.

13 Gutacker N, Bloor K, Cookson R, et al. Comparing hospital performance within and across countries: an illustrative study of coronary artery bypass graft surgery in England and Spain. Eur J Public Health 2015;25:28-34.

14 Goicolea Ruigómez FJ, Elola FJ, Durante-López A, et al. Coronary artery bypass grafting in Spain. Influence of procedural volume on outcomes. Rev Esp Cardiol 2020;73:488-94.

15 INEbase. Madrid: Instituto Nacional de Estadística (Spain). Available: http://www.ine.es/ [Accessed 20 Jul 2019].

16 Charlson M, Szatrowski TP, Peterson J, et al. Validation of a combined comorbidity index. J Clin Epidemiol 1994;47:1245-51.

17 Sun JW, Rogers JR, Her Q, et al. Validation of the combined comorbidity index of Charlson and Elixhauser to predict 30-day mortality across ICD-9 and ICD-10. Med Care 2018;56:812.

18 Epstein AJ, Polsky D, Yang F, et al. Coronary revascularization trends in the United States, 2001-2008. JAMA 2011;305:1769-76.

19 Windecker S, Kolh P, Alfonso F, et al. ESC/EACTS Guidelines on myocardial revascularization: The Task Force on Myocardial Revascularization of the European Society of Cardiology (ESC) and the European Association for Cardio-Thoracic Surgery (EACTS) Developed with the special contribution of the European Association of Percutaneous Cardiovascular Interventions (EAPCI). Eur Heart $J$ 2014;2014:2541-619.
20 Farkouh ME, Domanski M, Sleeper LA, et al. Strategies for multivessel revascularization in patients with diabetes. $N$ Engl $\mathrm{J}$ Med 2012;367:2375-84.

21 Becker ER, Granzotti AM. Trends in in-hospital coronary artery bypass surgery mortality by gender and race/ethnicity --1998-2015: why do the differences remain? J Natl Med Assoc 2019;111:527-39.

22 Cornwell LD, Omer S, Rosengart T, et al. Changes over time in risk profiles of patients who undergo coronary artery bypass graft surgery: the Veterans Affairs surgical quality improvement program (VASQIP). JAMA Surg 2015;150:308-15.

23 Beckmann A, Meyer R, Lewandowski J, et al. German heart surgery report 2018: the annual updated registry of the German Society for thoracic and cardiovascular surgery. Thorac Cardiovasc Surg 2019;67:331-44.

24 Vora AN, Dai D, Gurm H, et al. Temporal trends in the risk profile of patients undergoing outpatient percutaneous coronary intervention: a report from the National cardiovascular data registry's CathPCI registry. Circ Cardiovasc Interv 2016;9:e003070.

25 Taggart DP, Altman DG, Gray AM, et al. Randomized trial to compare bilateral vs. single internal mammary coronary artery bypass grafting 1 -year results of the arterial revascularisation trial (art). Eur Heart $J$ 2010;31:2470-81.

26 Shroyer AL, Hattler B, Wagner TH, et al. Five-Year outcomes after on-pump and off-pump coronary-artery bypass. $N$ Engl J Med 2017;377:623-32.

27 Brieger DB, Ng ACC, Chow V, et al. Falling hospital and postdischarge mortality following CABG in New South Wales from 2000 to 2013. Open Heart 2019;6:e000959.

28 Tran DT, Barake W, Galbraith D, et al. Total and cause-specific mortality after percutaneous coronary intervention: observations from the Alberta provincial project for outcome assessment in coronary heart disease registry. CJC Open 2019;1:182-9.

29 Spoon DB, Psaltis PJ, Singh M, et al. Trends in cause of death after percutaneous coronary intervention. Circulation 2014;129:1286-94.

30 Gutacker N, Bloor K, Cookson R, et al. Hospital surgical volumes and mortality after coronary artery bypass grafting: using international comparisons to determine a safe threshold. Health Serv Res 2017;52:863-78. 